At-Tijaroh : Jurnal Ilmu Manajemen dan Bisnis Islam

Volume 5 Nomor 1 Ed. Jan - Juni 2019 : Hal 52 - 66

p-ISSN : $2356-492 x$

e-ISSN : $2549-9270$

\title{
PENGELOLAAN BISNIS PERHOTELAN SYARIAH
}

\author{
Muhammad Riza Hafizi ${ }^{1}$, Dyah Sulistiyo Rimbodo² \\ 1,2 Institut Agama Islam Negeri Palangka Raya \\ 1,2 Jalan. G. Obos, Komplek Islamic Centre, Palangka Raya, Kalimantan Tengah \\ E-mail: riza.hafizi@iain-palangkaraya.ac.id
}

\begin{abstract}
The government has made regulations regarding the regulation of Sharia Hotels reviewed through the National Sharia Council-Indonesian Ulama Council concerning Minister of Tourism and Creative Economy Regulation Number 2 of 2014. Hotel Jamrud Syariah, one of the hotels in Central Kalimantan which is a family business managed with three aspects namely products, service and management. The purpose of the study was to analyze how the management of the sharia hotel business at the Islamic Jamrud Hotel. This research is a field research using descriptive qualitative research methods. The subjects of this study are the owners, employees and visitors of the Sharia Jamrud Hotel in Pangkalan Bun. Data analysis techniques using collection data, data reduction, data display, and conclusion drawing. The results of this study indicate that the management of the Pangkalan Bun Syariah Jamrud hotel has been well managed. Then the management of sharia business hotels at the Islamic Jamrud Hotel has fulfilled the absolute criteria if viewed from the National Sharia Council-Indonesian Ulema Council regarding Minister of Tourism and Creative Economy Regulation Number 2 of 2014.
\end{abstract}

Keywords: Products, Services, Management

\begin{abstract}
Abstrak
Pemerintah telah membuat peraturan tentang regulasi Hotel Syariah ditinjau melalui Dewan Syariah Nasional-Majelis Ulama Indonesia mengenai Peraturan Menteri Pariwisata dan Ekonomi Kreatif Nomor 2 Tahun 2014. Hotel Jamrud Syariah, salah satu hotel di Kalimantan Tengah yang merupakan bisnis keluarga yang dikelola dengan tiga aspek yaitu produk, pelayanan dan pengelolaan. Tujuan penelitian adalah untuk menganalisis bagaimana pengelolaan bisnis perhotelan syariah pada Hotel Jamrud Syariah. Penelitian ini merupakan penelitian lapangan menggunakan metode penelitian kualitatif deskriptif. Adapun subjek penelitian ini adalah pemilik, karyawan dan pengunjung Hotel Jamrud Syariah Pangkalan Bun. Teknik analisis data menggunakan data collection, data reduction, data display, dan conclusion drawing. Hasil dari penelitian ini menunjukkan bahwa pengelolaan hotel Jamrud Syariah Pangkalan Bun sudah dikelola secara baik. Kemudian pengelolaan perhotelan bisnis syariah pada Hotel Jamrud Syariah sudah memenuhi kriteria mutlak jika ditinjau dari Dewan Syariah Nasional-Majelis Ulama Indonesia mengenai Peraturan Menteri Pariwisata dan Ekonomi Kreatif Nomor 2 Tahun 2014.
\end{abstract}

Kata Kunci: Produk, Pelayanan, Pengelolaan 


\section{3 | Pengelolaan Bisnis Perhotelan Syariah}

\section{PENDAHULUAN}

Indonesia yang merupakan negara dengan penduduk muslim terbesar dan terbentang luas alam yang indah serta budaya yang tak kalah menarik tentu akan menjadi ikon wisata dunia baru apabila industri pariwisata dikelola dengan baik. Untuk memajukan pariwisata Indonesia dapat ditempuh dengan cara pendekatan atau menempatkannya dalam bingkai syariah. Pariwisata syariah bukan hanya wisata religi saja seperti tempat-tempat ibadah, makam para wali, maupun peninggalan sejarah, melainkan mencakup hal lain yang lebih luas dengan melibatkan banyak industri di dalamnya seperti, restoran, spa, sauna, biro perjalanan wisata syariah serta hotel syariah. Hal ini telah menandakan bahwa sistem ekonomi syariah telah berkembang cukup luas dari awalnya hanya meliputi perdagangan produk halal, berkembang ke industri keuangan dan sekarang berkembang ke gaya hidup yang dapat berupa keramah-tamahan, rekreaasi, perawatan dan kesehatan dan lain sebagainya (Sofyan, 2012).

Konsep pariwisata syariah telah lebih dulu ditekuni oleh negara tetangga kita yang menamakan dirinya "The Trully Asia”. Malaysia memulai pariwisata syariah sebelum banyak dilirik oleh negara lain, sehingga saat ini menjadi negara nomor satu yang paling banyak dikunjungi oleh wisatawan muslim. Menurut data Cresent Rating dan Dinar Standart, para turis muslim global nilainya mengalahkan pasar wisata Amerika Serikat, Jerman, China, Inggris atau India. Setiap tahun, uang yang dikeluarkan oleh para turis muslim, diperkirakan mencapai US\$ 126 miliar (Rp. 1.222 triliun). Angka ini nyaris menyamai Anggaran Pendapatan dan Belanja Negara (APBN) Indonesia dan juga lebih tinggi dari pengeluaran wisatawan Jerman yang mencapai US\$ 111 miliar (Rp. 1.077 triliun). Angka itu juga lebih tinggi dari total uang yang dikeluarkan seluruh wisatawan Amerika Serikat yang mencapai US\$ 93 miliar (RP. 902 triliun) atau China yang mencapai US\$ 65 miliar (RP. 630 triliun). Data tersebut belum termasuk wisata religi seperti haji dan umrah (Nirwandar, 2013)

\section{Tabel 1.1}

Jumlah Wisatawan Mancanegara

\begin{tabular}{|l|c|c|c|c|c|}
\hline & $\mathbf{2 0 1 1}$ & $\mathbf{2 0 1 2}$ & $\mathbf{2 0 1 3}$ & $\mathbf{2 0 1 4}$ & $\mathbf{2 0 1 5}$ \\
\hline $\begin{array}{l}\text { Wisatawan } \\
\text { mancanegara }\end{array}$ & 7,6 juta & $\begin{array}{c}\text { 8 juta } \\
\text { (meningkat } \\
5,04 \%)\end{array}$ & $\begin{array}{c}8,8 \text { juta } \\
\text { (meningkat } \\
9 \%)\end{array}$ & $\begin{array}{c}9,4 \text { juta } \\
\text { (meningkat } \\
9,3 \%)\end{array}$ & $\begin{array}{c}10,4 \text { juta } \\
\text { (meningkat } \\
10,29 \%)\end{array}$ \\
\hline
\end{tabular}

Sumber: www.kemenpar.go.id

Data diatas merupakan data perkembangan wisatawan mancanegara menurut 19 pintu masuk pada tahun 2011-2015. Data tersebut menunjukkan bahwa secara umum prospek industri perhotelan di Indonesia menjanjikan walaupun cenderung lambat. Terbukti dalam lima tahun terakhir yakni dari tahun 2011 hingga 2015 tingkat kunjungan wisatawan mancanegara dari tahun ke tahun mengalami peningkatan dan bahkan disebut sebagai 
penyumbang 5\% Pendapatan Domestik Bruto (PDB). Keberadaan hotel merupakan hal yang sangat vital. Pariwisata indonesia juga ditopang oleh kunjungan wisatawan mancanegara (wisman) yang tahun 2012 tumbuh 5,04\% yakni dari 7,6 juta pada 2011 meningkat menjadi 8 juta pada 2012. Jumlah tersebut semakin meningkat pada tahun 2013 menjadi 8,8 juta di tahun 2015 menjadi 10,4 juta wisatawan mancanegara. Perhotelan dan pariwisata adalah dua industri yang tak terpisahkan. Hotel memerlukan wisatawan yang mengunjungi obyek wisata sebagai calon tamu yang menginap dan memberi pendapatan pada hotel. Bila suatu obyek wisata terkenal dan ramai dikunjungi maka hotel di sekitarnya juga akan banyak diinapi (kompasiana, 2017).

Usaha hotel syariah adalah usaha hotel yang penyelenggaraannya harus memenuhi prinsip-prinsip syariah sebagaimana diatur oleh fatwa dan/atau telah disetujui oleh Dewan Syariah Nasional Majelis Ulama Indonesia (DSN-MUI). Penggolongan kegiatan bisnis perhotelan secara syariah, secara spesifik dijelaskan dalam standar hotel syariah dari DSNMUI, sebagai regulasi dan pedoman perhotelan syariah. Terdapat tiga aspek yang tercantum dalam peraturan tersebut, yaitu aspek produk, pelayanan dan pengelolaan. Aspek produk meliputi unsur toilet umum, kamar tidur tamu, kamar spa. Aspek pelayanan meliputi unsur kantor depan, tata graha, makan dan minum, olahraga, rekreasi dan kebugaran, spa dan fasilitas hiburan. Aspek terakhir, yaitu pengelolaan meliputi unsur manajemen usaha dan sumber daya manusia (Janitra, 2017).

Provinsi Kalimantan Tengah sendiri khususnya di Kabupaten Kotawaringin Barat, Hotel Jamrud Syariah merupakan hotel pertama yang berdiri dengan melabelkan namanya berbasis syariah. Hotel Jamrud Syariah berdiri sejak tahun 2014 tepat beberapa bulan setelah dikeluarkannya Peraturan Menteri Pariwisata dan Ekonomi Kreatif Nomor 2 Tahun 2014 dan hingga kini masih dikelola dan dikembangkan sebagai usaha bisnis syariah. Hotel tersebut berdiri untuk memenuhi kebutuhan akomodasi wisatawan muslim akan hotel yang bebas dari unsur-unsur yang melanggar prinsip syariah. Kemudian karena banyaknya owner yang menginginkan penginapan yang berbasis syariah. Selain itu, Hotel Jamrud Syariah ini memiliki letak yang strategis yaitu terletak di salah satu jalan utama Pangkalan Bun tepatnya dijalan Prakusuma Yudha No.3, Mendawai, Arut Selatan, Kabupaten Kotawaringin Barat. Hotel ini merupakan hotel yang dapat menjadi panutan bagi hotel-hotel yang lain yang ada di Pangkalan Bun ketika memutuskan dirinya menjadi Hotel Syariah. Selain daripada itu, dengan melabelkan dirinya menjadi Syariah, hal ini menjadikan nilai positif tersendiri bagi pengunjung Hotel. Kemudian, dengan keluarnya peraturan yang diatur dalam Peraturan Menteri Pariwisata dan Ekonomi Kreatif Nomor 2 Tahun 2014 akan menjadi acuan bagi Hotel Jamrud syariah untuk lebih mengoptimalkan dirinya menjadi hotel berbasis syariah di Pangkalan Bun. 
Tabel 1.2

Data Wisatawan Mancanegara dan Wisatawan Nusantara di Kalimantan Tengah

\begin{tabular}{|c|c|c|c|c|c|c|c|c|c|}
\hline \multirow{3}{*}{ No } & \multirow{3}{*}{ Kab/Kot } & \multicolumn{4}{|c|}{ Wisatawan Mancanegara } & \multicolumn{4}{|c|}{ Wisatawan Nusantara } \\
\hline & & \multicolumn{4}{|c|}{ Tahun } & \multicolumn{4}{|c|}{ Tahun } \\
\hline & & 2014 & 2015 & 2016 & $\mathbf{2 0 1 7}$ & 2014 & 2015 & 2016 & $\mathbf{2 0 1 7}$ \\
\hline 1 & $\begin{array}{c}\text { Kotawaringin } \\
\text { Barat }\end{array}$ & 10986 & 9767 & 10.744 & 12.097 & 14.676 & 53.514 & 102.430 & 98.168 \\
\hline 2 & $\begin{array}{c}\text { Kotawaringin } \\
\text { Timur }\end{array}$ & 4 & 6 & 116 & 30 & 30.050 & 60.450 & 89.910 & 54.273 \\
\hline 3 & Lamandau & 278 & 93 & 158 & 30 & 0 & 4.073 & 5.665 & 30.100 \\
\hline 4 & Sukamara & 10 & 10 & 12 & 12 & 13.050 & 18.600 & 19.460 & 51 \\
\hline 5 & Seruyan & $\mathrm{O}$ & $\mathrm{O}$ & 10 & 10 & 34.289 & 42.168 & 43.385 & 45.000 \\
\hline 6 & Katingan & O & O & 56 & 56 & 32.407 & $34 \cdot 351$ & 37.853 & 37.152 \\
\hline 7 & Gunung Mas & 24 & 24 & 72 & 32 & 4.890 & 6.115 & 6.758 & 7.800 \\
\hline 8 & Pulang Pisau & 618 & 176 & 212 & 112 & 3.648 & 1.779 & 1.957 & 2.000 \\
\hline 9 & Kapuas & 31 & 0 & 35 & 35 & $\mathrm{O}$ & 0 & 1.551 & 6.351 \\
\hline 10 & Barito Selatan & & $\mathrm{O}$ & 10 & 10 & 8.557 & 22.554 & 24.809 & 16.524 \\
\hline 11 & Barito Timur & 38 & 37 & 52 & O & 10.957 & 11.104 & 13.969 & 10.969 \\
\hline 12 & Barito Utara & 275 & O & 187 & & 40.427 & 43.809 & 44.190 & 48.190 \\
\hline 13 & Murung Raya & O & 37 & 77 & & & 1.537 & 1.691 & 41.691 \\
\hline 14 & $\begin{array}{c}\text { Kota Palangka } \\
\text { Raya }\end{array}$ & 1012 & 3853 & 7117 & 942 & 5.236 & 39.676 & 391.804 & 67.591 \\
\hline
\end{tabular}

Sumber: Dinas Pariwisata dan Kebudayaan Provinsi Kalimantan Tengah

Berdasarkan data diatas terlihat bahwa Kotawaringin Barat memiliki tingkat pengunjung terbanyak dibanding kabupaten/kota lain yang ada di Kalimantan Tengah. Hal itu menunjukkan bahwa tingkat menginap lebih besar dibanding kabupaten/kota yang ada di Kalimantan tengah. Terlebih lagi Kabupaten Kotawaringin Barat memiliki kekayaan alam yang potensial untuk dikembangkan menjadi tempat pariwisata, seperti wisata hutan, bahari dan budayanya. Berdasarkan pemaparan di atas, penulis ingin meneliti lebih lanjut pengelolaan pada Hotel Jamrud Syariah Pangkalan Bun ditinjau dari Peraturan Menteri Pariwisata dan Ekonomi Kreatif Republik Indonesia Nomor 2 Tahun 2014 tentang Pedoman Penyelenggaraan Usaha Hotel Syariah. Dari uraian di atas penulis tertarik untuk meneliti tentang Pengelolaan Bisnis Perhotelan Syariah pada Hotel Jamrud Syariah Pangkalan Bun. 


\section{TINJAUAN TEORITIK}

Manajemen merupakan suatu proses untuk mewujudkan suatu keinginan yang hendak dicapai atau yang di inginkan oleh sebuah organisasi, baik organisasi bisnis, organisasi sosisal, organisasi pemerintah dan sebagainya. Manajemen adalah pengelolaan suatu pekerjaan untuk memperoleh hasil dalam rangka pencapaian tujuan yang telah ditentukan dengan cara menggerakkan orang-orang lain untuk bekerja. Fungsi-fungsi pokok manajemen menurut George R. Terry sebagai berikut yaitu pertama, Perencanaan merupakan suatu proses penentuan sasaran yang ingin dicapai, tindakan yang akan diambil, bentuk organisasi yang tepat untuk mencapainya, dan SDM yang bertanggung jawab terhadap kegiatan-kegiatan yang akan dilakukan. George R. Terry dan Leslie W.R memberikan definisi bahwa perencanaan adalah proses memutuskan tujuan-tujuann yang akan dikejar selama jangka waktu yang akan datang dan hal-hal yang akan dilaksanakan agar tujuan-tujuan itu dapat tercapai. Robbins dan Coulter mendefinisikan perencanaan sebagai proses yang dimulai dari penetapan tujuan organisasi menentukan strategi untuk pencapaian tujuan organisasi tersebut secara menyeluruh, serta merumuskan sistem perencanaan yang menyeluruh untuk mengintegrasikan dan mengkoordinasikan seluruh pekerjaan organisasi hingga tercapainya tujuan organisasi. Dari definisi diatas, dapat disimpulkan bahwa perencanaan adalah suatu proses untuk menentukan visi, misi, tujuan dan sasaran yang diinginkan guna mencapai tujuan yang diinginkan pada masa yang akan datang sesuai dengan syariat Islam. Kedua, Pengorganisasian merupakan fungsi manajemen yang menggabungkan sumber daya manusia dan bahan melalui struktur formal dari tugas dan kewenangan. Hasil dari proses pengorganisasian adalah organisasi adalah sekelompokorang yang bekerja sama untuk mencapai tujuan bersama. Jika dalam fungsi perencanaan tujuan dan rencana ditetapkan, maka dalam pengorganisasian rencana tersebut diturunkan dalam pembagian kerja tertentu. Sebagaimana dikemukakan oleh Stoner, ada empat pilar (building bloks) yang menjadi dasar untuk melakukan proses pengorganisasian, keempat pilar tersebut adalah pembagian kerja (division of work), pengelompokkan pekerjaan (departmentalization), penelitian relasi antarbagian dalam organisasi (hierarchy), serta penentuan mekanisme untuk mengintegrasikan aktivitas antarbagian dalam organisasi atau kordinasii (coordination).

Ketiga, Pengarahan adalah fungsi manajer yang amat penting. Semua usaha kelompok memerlukan pengarahan kalau menginginkan usaha itu berhasil dalam mencapai tujuan-tujuan kelompok. Pengarahan adalah kegiatan pimpinan untuk membimbing, menggerakkan, mengatur segala kegiatan yang tidk diberikan dalam melaksanakan kegiatan usaha. Pengarahan berarti menentukan bagi anggota tentang apa yang harus mereka kerjakan atau tidak boleh mereka kerjakan. Pengarahan mencakup berbagai proses operasi standar, pedoman dan buku panduan, bahkan manajemen berdasarkan sasaran. Pengarahan 


\section{7 | Pengelolaan Bisnis Perhotelan Syariah}

merupakan metode untuk menyalurkan perilaku individu dalam aktivitas tertentu dan menghindari aktivitas lain dengan menetapkan peraturan dan standar, kemudian memastikan bahwa peraturan tersebut dipatuhi. Keempat, Pengendalian merupakan proses pemonitoran kegiatan organisasional untuk mengetahui apakah kinerja aktual sesuai dengan tujuan organisasional yang diharapkan. Sebagai suatu proses maka pengendalian adalah kegiatan penetapan standar kerja, monitoring dan pengukuran kinerja, membandingkan hasil kinerja aktual hasil pengukuran dengan standar yang telah dibuat, serta mengambil tindakan korektif dan penyesuaian atau pengembangan bilamana dibutuhkan. pengendalian adalah penting karena ia merupakan jaringan terakhir dalam fungsi-fungsi manajemen. Pengendalian penting untuk menentukan efisiensi dan efektivitas keberhasilan pengelolaan mencapi tujuan. Pengendalian dilakukan agar kegiatan organisasional untuk mencapai tujuan dilakukan sesuai dengan rencana yang telah ditetapkan sebelumnya

\section{METODE PENELITIAN}

\subsection{Jenis, Waktu dan Tempat Penelitian}

Penelitian ini merupakan penelitian lapangan (field research) menggunakan penelitian kualitatif deskriptif. Pendekatan kualitatif deskriptif sebagaimana pendapat Lexy J. Moleong adalah suatu penelitian yang akan mengumpulkan katakata, gambar, dan bukan angka, dengan demikian, laporan penelitian akan berisi kutipan-kutipan data untuk memberi gambaran penyajian laporan tersebut. Penelitian ini dilakukan mulai bulan Februari sampai bulan Agustus 2018 dan penelitian berlokasi di Jl. Prakusuma Yudha No.3, Mendawai, Arut Sel., Kabupaten Kotawaringin Barat, Kalimantan Tengah.

\subsection{Objek dan Subjek Penelitian}

Objek penelitian yang sesuai dalam permasalahan dalam penelitian ini yaitu "Pengelolaan Bisnis Pehotelan Syariah di Hotel Jamrud Syariah Pangkalan Bun, Kabupaten Kotawaringin Barat kalimantan Tengah". subjek penelitian ini menggunakan teknik purposive sampling berdasarkan kriteria yang diambil oleh peneliti. Maka dalam hal ini, yang menjadi subjek penelitian diantaranya ialah pihak manager, pegawai Hotel Jamrud Syariah yang merupakan bagian yang terlibat dalam proses pengelolaan Hotel dan mengetahui perkembangan Hotel Jamrud Syariah serta informan meliputi Pengunjung Hotel yang merupakan pengunjung yang menginap di Hotel Jamrud Syariah Pangkalan Bun.

\subsection{Teknik Pengumpulan Data}

Dalam penelitian ini, peneliti menggunakan beberapa teknik atau metode pengumpulan data. Guna mendukung pencarian data yang valid dan sesuai dengan realita yang ada. Adapun teknik yang digunakan adalah menggunakan wawancara, 
obeservasi dan dokumentasi. Wawancara sebagaimana yang diutarakan Estenberg " $a$ meeting of two persons to change information and idea through question and responses, resulting in communication and joint construction of meaning about a particular topic". Wawancara adalah merupakan pertemuan dua orang untuk bertukar informasi dan ide melalui tanya jawab, sehingga dapat dikonstruksikan makna dalam suatu topik tertentu. Dalam hal ini adalah segala informasi yang berhubungan dengan produk, pelayanan dan pengelolaan yang ada pada Hotel Jamrud Syariah Pangkalan Bun.

\subsection{Pengabsahan Data}

Keabsahan data yang peneliti gunakan adalah teknik triangulasi. Teknik triangulasi adalah teknik pemeriksaan keabsahan data yang memanfaatkan sesuatu yang lain di luar data itu untuk keperluan pengecekan atau sebagai pembanding terhadap data itu. Menurut Denzin yang dikutip Moleong ada empat macam triangulasi sebagai teknik pemeriksaan yang memanfaatkan penggunaan sumber, metode, penyidik, dan teori.

Triangulasi yang peneliti gunakan dalam penelitian ini meliputi triangulasi teori dan triangulasi sumber. Triangulasi teori yaitu membandingkan beberapa teori yang terkait secara langsung dengan data penelitian. Triangulasi dengan sumber berarti membandingkan dan mengecek balik derajat kepercayaan suatu informasi yang diperoleh melalui waktu dan alat yang berbeda dalam metode kualitatif.

\subsection{Teknik Analisis Data}

Dalam analisi data diperlukan beberapa tahapan, seperti yang diungkapkan Bungin dalam bukunya Analisis Data Penelitian Kualitatif, yakni data collection atau koleksi data adalah pengumpulan data dengan analisis data, yang mana data tersebut diperoleh selama melakukan pengumpulan data tanpa proses pemilahan. Data reduction, yaitu pengolahan data yang mencakup kegiatan mengikhtiarkan hasil pengumpulan data selengkap mungkin, dan memilah-milahnya kedalam satuan konsep tertentu, kategori tertentu atau tema tertentu. Data display atau penyajian data ialah data yang dari kencah penelitian dipaparkan secara ilmiah oleh peneliti dengan tidak menutupi kekurangan. Conclusion drawing atau penarikan kesimpulan dengan melihat kembali pada reduksi data display sehingga kesimpulan yang diambil tidak menyinggung.

\section{HASIL DAN PEMBAHASAN}

Berdasarkan hasil wawancara yang telah peneliti lakukan dengan subjek-subjek penelitian diketahui dalam pengelolaan Bisnis Perhotelan Syariah Pada Hotel Jamrud Syariah Pangkalan Bun akan peneliti uraikan dalam sub bab ini. Adapun pembahasan dalam 


\section{9 | Pengelolaan Bisnis Perhotelan Syariah}

sub bab ini terbagi menjadi empat kajian utama sesuai dengan rumusan masalah pertama, pengelolaan Hotel Jamrud Syariah Pangkalan Bun. Kedua produk perhotelan syariah pada Hotel Jamrud Syariah Pangkalan Bun ditinjau dari Dewan Syariah Nasional-Majelis Ulama Indonesia. Ketiga, pelayanan perhotelan syariah pada Hotel Jamrud Syariah ditinjau dari Dewan Syariah Nasional-Majelis Ulama Indonesia dan yang terakhir mengenai pengelolaan perhotelan syariah pada Hotel Jamrud Syariah Pangkalan Bun ditinjau Dewan Syariah Nasional-Majelis Ulama Indonesia mengenai Peraturan Menteri Pariwisata dan Ekonomi Kreatif Tahun 2014.

\subsection{Pengelolaan pada Hotel Jamrud Syariah Pangkalan Bun}

Hotel jamrud syariah Pangkalan Bun telah menerapkan fungsi manajemen yaitu perencanaan, pengorganisasian, pengarahan dan serta pengawasan dengan baik dan efessien hal tersebut tercermin dari Perencanaan Hotel Jamrud Syariah Pangkalan Bun dalam usaha perhotelannya terbilang sudah cukup baik. Hal tersebut terbukti dengan kondisi Hotel Jamrud Syariah sendiri yang mulai berdiri sejak tahun 2014 masih terus bertahan dan berkembang hingga sekarang. Bisnis keluarga ini benar-benar dikelola oleh satu keluarga saja, tanpa ada campur tangan pihak lain yang ikut membantu kecuali pegawainya yang diambil dari masyarakat sekitar tanpa melihat tingkat pendidikannya. Didirikannya hotel Jamrud Syariah ini, karena pemilik sendiri ingin membantu anak-anak sekitar yang masih belum memiliki pekerjaan agar bisa terbantu, selain itu juga pemilik menginginkan sebuah usaha yang mendapatkan keberkahan bukan hanya keuntungan semata. Mulai berdiri dari Maret 2014, Hotel Jamrud Syariah terus memperbaiki kualitas Hotel agar dapat memuaskan keinginan pengunjung. Berdasarkan uraian diatas, peneliti menyimpulkan bahwa perencanaan yang dilakukan Hotel Jamrud Syariah sudah merencanakan awal berdirinya Hotel Jamrud Syariah sampai berjalannya hingga sekarang dengan baik dan efektif.

Setelah tahap perencanaan sudah dilakukan, hal yang perlu dilakukan oleh Hotel Jamrud Syariah adalah pengorganisasian. Melalui pengorganisasian yang baik, peran orang-orang yang ada di Hotel menjadi lebih jelas dan terstruktur. Jika dalam fungsi perencanaan tujuan dan rencana ditetapkan, maka dalam pengorganisasian rencana tersebut diturunkan dalam pembagian kerja tertentu. Sebagaimana dikemukakan oleh Stoner, ada empat pilar (building bloks) yang menjadi dasar untuk melakukan proses pengorganisasian, keempart pilar tersebut adalah pembagian kerja, pengelompokkan pekerjaan, penentuan relasi antarbagian dalam organisasi, serta penentuan mekanisme untuk mengintegrasikan aktivitas antarbagian dalam organisasi atau koordinasi. Jika dikaitkan dengan teori pengorganisasian bahwa pengorganisasian yang ada pada Hotel Jamrud Syariah Pangkalan Bun sudah 
terbentuk sejak awal didirikan. Didalam struktur pengorganisasian, sudah terlihat jelas pembagian tugas dari mulai manajer hotel sampai karyawan hotel. Hal ini membuat karyawan yang ada di Hotel Jamrud Syariah dapat melakukan tugasnya secara baik dan bertanggung jawab. Selain itu, membuat usaha perhotelan Jamrud Syariah lebih terstruktur dan terorganisir.

Pengarahan berarti menentukan bagi anggota tentang apa yang harus mereka kerjakan atau tidak boleh mereka kerjakan. Setelah struktur organisasi dibuat maka sudah pasti setiap jabatan yang ada di Hotel Jamrud Syariah memiliki perannya masing-masing. Di dalam Hotel Jamrud Syariah, karena ini merupakan bisnis keluarga. Pemilik hotel sendiri lah yang akan memberikan arahan-arahan terhadap karyawannya. Manajer yang memberi dan mengajari tugas yang wajib dilakukan masing-masing karyawannya agar usaha perhotelan dapat berjalan lancar sesuai dengan usaha perhotelan syariah semestinya. Selain itu, pemilik juga menerapkan aturan Dewan Syariah Nasional-Majelis Ulama Indonesia sebagai standar acuan dalam menjalankan usahanya. Jadi menurut peneliti bahwa tujuan dari pengarahan adalah meneruskan suatu usaha yang sudah direncanakan secara matang, dimana setelah rencana tersebut dibuatlah struktur organisasi yang isinya terdapat tugastugas dari setiap karyawan yang ada di Hotel Jamrud Syariah Pangkalan Bun kemudian tugas tersebut kembali diarahkan oleh pemilik hotel agar dapat berjalan dengan baik, efisien dan terstruktur.

Pengendalian adalah fungsi terakhir dari proses pengelolaan. Fungsi ini adalah salah satu fungsi yang sangat penting dan sangat menentukan pelaksanaan pengelolaan karena itu harus dilakukan dengan sebaik-baiknya. Semua fungsi terdahulu tidak akan berjalan secara efektif tanpa adanya fungsi pengawasan. Pengawasan adalah penemuan dan penerapan cara untuk menjamin bahwa rencana telah dilaksanakan sesuai dengan yang telah ditetapkan. Pengendalian yang dilakukan oleh Hotel Jamrud Syariah dalam usaha perhotelannya merupakan suatu media untuk mengontrol atau mengawasi terhadap pengelolaan bisnis Hotel tersebut. Pengontrolan tersebut dilakukan langsung oleh pemilik Hotel Jamrud Syariah beserta istri yang dilakukan setiap hari secara langsung maupun tidak langsung. Secara langsung, pemilik langsung datang mengawasi produk, pelayanan dan pengelolaan sumber daya manusianya. Pengawasan secara tidak langsung diawasi melalui CCTV yang ada di hotel yang langsung tersambung ke handphone pemilik Hotel Jamrud Syariah Pangkalan Bun. Tujuan pengendalian dalam Hotel Jamrud Syariah sendiri bertujuan untuk memberi pengawasan terhadap produk, pelayanan dan pengelolaan yang menjadi daya jual Hotel Jamrud Syariah Pangkalan Bun. Selain itu, pengendalian juga bertujuan untuk tetap menjaga komitmen dari Hotel Jamrud 
Syariah Pangkalan Bun agar tidak melewati batas dari Syariat Islam. Berdasarkan uraian diatas, peneliti mengambil sebuah kesimpulan bahwa pengelolaan Hotel Jamrud Syariah Pangkalan Bun sudah berjalan dengan sebagaimana mestinya. Hal tersebut sudah terlihat dari pengelolaan yang sudah dikelola secara serius, mulai dari perencanaan, hingga tugas masing-masing karyawan sudah terorganisir secara baik.

\subsection{Produk Perhotelan Syariah Pangkalan Bun Ditinjau dari Dewan Syariah Nasional - Majelis Ulama Indonesia Mengenai Peraturan Menteri Pariwisata dan Ekonomi Kreatif Nomor 2 Tahun 2014}

Sebagai Industri yang bergerak di bidang jasa, Hotel Jamrud Syariah Pangkalan Bun tentunya sangat mementingkan kepuasan pengunjung hotel. Salah satu faktor yang perlu diperhatikan untuk mencapai kepuasan pengunjung hotel adalah produk dan layanan yang ada pada Hotel Jamrud Syariah Pangkalan Bun. Pada sistem pengelolaan yang ada pada Hotel Jamrud Syariah menerapkan Sistem Jaminan Halal dimana Sistem Jaminan Halal tersebut berdasarkan peraturan Dewan Syariah Nasional-Majelis Ulama Indonesia mengenai peraturan Menteri Pariwisata dan ekonomi Kreatif Nomor 2 Tahun 2014. 1)

Dikaji dengan teori produk berdasarkan Dewan Syariah Nasional-Majelis Ulama Indonesia Hotel Jamrud Syariah selalu mengedepankan peraturan Dewan Syariah-Majelis Ulama Indonesia sebagai dasar acuannya. Dengan membuka usaha perhotelan Syariah, membuat Hotel Jamrud Syariah selalu mengedepankan aturanaturan Syariah. Peneliti akan memaparkan produk-produk yang ada di dalam Hotel Jamrud Syariah Pangkalan Bun sebagai berikut: pertama, Peneliti melakukan observasi dan wawancara kepada pemilik hotel, karyawan dan pengunjung. Dari ketiga subjek yang diwawancarai, dapat disimpulkan bahwa toilet umum Hotel Jamrud Syariah Pangkalan Bun berbentuk kamar mandi untuk satu orang dan tertutup bukan toilet besar yang dapat dimasuki oleh beberapa orang yang memerlukan pemisah untuk menjaga pandangan. Kelebihan yang ada pada toilet umum Hotel Jamrud Syariah Pangkalan Bun telah terdapat peralatan praktis untuk bersuci seperti gayung, bak mandi, sabun, shower, kloset dan keran air untuk berwudhu. Hal ini merupakan peralatan yang lazim digunakan untuk bersuci sehingga telah sesuai dengan peraturan Dewan Syariah Nasional-Majelis Ulama Indonesia. Kedua, berdasarkan observasi dan wawancara yang peneliti lakukan di Hotel Jamrud Syariah Pangkalan Bun, peneliti menjumpai adanya informasi yang tertulis di meja receptionis yang ada di lobby hotel, yaitu adanya tipe kamar dan harganya. Kemudian selain itu juga terdapat tata tertib Hotel Syariah Pangkalan Bun yang salah satu ketentuannya tidak diperbolehkan tamu non muhrim menyewa kamar dalam satu kamar. Peraturan ini dibuat untuk menjaga nilai syariah pada 
lingkungan Hotel Jamrud Syariah Pangkalan Bun. Ketiga, Berdasarkan hasil observasi dan wawancara, peneliti menjumpai di kamar tamu, diantaranya: Hotel Jamrud Syariah Pangkalan Bun telah menyediakan sajadah di seluruh kamar tidur tamu yang ingin melakukan ibadah di dalam kamar. Hal ini juga terdapat pada kriteria mutlak yang harus ada pada kamar tidur tamu hotel syariah. Kedua, pihak hotel juga telah menyediakan al-qur'an di setiap kamar tamu agar tamu yang menginap juga dapat membaca al-quran di dalam kamar mereka. Ketiga, tidak tersedianya akses pornografi dan tindakan asusila. Bagi tamu non muhrim yang ingin bertemu harap menemuinya di lobby. Untuk setiap kamar, pihak manajemen hotel juga menyediakan TV Kabel, dimana tv kabel tersebut terdapat saluransaluran televisi lokal maupun internasional yang islami sehingga tamu tidak dapat menyalahgunakan fasilitas hotel untuk tujuan diluar syariah Islam. Keempat, tidak ada minuman beralkohol di mini bar. Di dalam kamar tidur tamu, pihak hotel menyediakan minuman berupa air mineral, teh atau kopi. Ruang Ibadah pada Hotel Jamrud Syariah Syariah bukanlah ruang ibadah seperti mushalla namun hanya berbentuk ruangan kecil saja. Ruang ibadah yang ada di Hotel Jamrud Syariah ada satu di lantai satu. Keadaan ruang ibadah dalam kondisi bersih dan terawatt dan tersedia peralatan shalat yang baik, suasana tempat ibadah juga diperhatikan dengan adanya pencahayaan yang cukup terang dan sirkulasi udara yang baik. Manajemen hotel juga telah menyediakan karpet sajadah dan mukena di ruang ibadah tersebut.

\subsection{Pelayanan Perhotelan Syariah pada Hotel Jamrud Syariah Ditinjau dari Dewan Syariah Nasional - Majelis Ulama Indonesia Mengenai Peraturan Menteri Pariwisata dan Ekonomi Kreatif Nomor 2 Tahun 2014}

Berdasarkan hasil wawancara pada Hotel Jamrud Syariah pangkalan Bun dalam hal pelayanan berdasarkan Dewan Syariah Nasional-Majelis Ulama Indonesia sebagai berikut adalah Pelayanan yang ada di Hotel Syariah berdasarkan Peraturan Menteri Pariwisata dan Ekonomi Kreatif Nomor 2 Tahun 2014 setidaknya harus memiliki 6 (enam) unsur yaitu, kantor depan, tata graha, makan dan minum, (olahraga, rekreasi dan kebugaran), SPA dan fasilitas hiburan. Namun Hotel Jamrud Syariah hanya memenuhi 3 (tiga) unsur yang ada berdasarkan Peraturan Menteri Pariwisata dan Ekonomi Kreatif Nomor 2 Tahun 2014 tersebut yakni kantor depan, tata graha serta makan dan minum. Pertama, pelayanan bagian kantor depan yang diberikan karyawan kepada pengunjung dimana yang pertama sekali dilakukan oleh petugas front office yaitu melakukan seleksi terhadap tamu yang datang berpasangan. Minimal tamu yang datang berpasangan jika tidak membawa buku nikah harus dapat 
menunjukkan Kartu Tanda Penduduk (KTP) yang beralamatkan sama. Kedua, Memberikan informasi masjid terdekat dengan hotel. Ketiga, memberikan informasi jadwal waktu sholat. Petugas front office memberikan informasi mengenai jadwal waktu sholat kepada tamu yang belum mengetahui jadwal waktu sholat untuk daerah Pangkalan Bun. Keempat, petugas front office memberikan informasi mengenai kegiatan bernuansa Islami. Kelima, petugas front office juga memberikan informasi mengenai restoran/rumah makan halal. Kedua, pelayanan yang diberikan karyawan terhadap pengunjung Hotel Jamrud Syariah dibagian tata graha yang pertama sekali, menyediakan perlengkapan shalat yang bersih dan terawat. Kedua, penyediaan AlQuran, Hotel Jamrud Syariah Pangkalan Bun menyediakan Al-Quran disetiap kamar hotel tamu. Hal ini bertujuan agar pengunjung dapat melakukan ibadah dengan membaca Al-Quran di dalam kamar. Ketiga, pelayanan yang diberikan oleh Hotel Jamrud Syariah untuk bagian makan dan minuman yang pertama adalah, tersedia pilihan makanan dan minuman halal, dimana menu makanan dan minuman yang ada di Hotel Jamrud Syariah berasal dan diolah dari bahan-bahan yang halal. Sehingga para tamu tidak perlu cemas akan kehalalan yang disajikan oleh pihak Hotel Jamrud Syariah. Kedua, Menyediakan makan sahur pada bulan ramadhan. Dengan melaksanakan 3 unsur tersebut, manajemen hotel beranggapan telah menerapkan layanan dasar yang dibutuhkan oleh tamu atas akomodasi hotel syariah. Tiga unsur selanjutnya yaitu (olahraga, rekreasi, dan kebugaran, Spa, dan fasilitas hiburan merupakan layanan tambahan yang dinilai kurang tepat bagi Hotel Jamrud Syariah Pangkalan Bun karena membutuhkan tanah yang lebih luas dan selain itu, ketiga unsur tersebut masuk dalam kategori tidak mutlak hilal 1 Peraturan Menteri Pariwisata dan Ekonomi Kreatif Nomor 2 Tahun 2014.

Peneliti menilai, ketiga unsur pelayanan tersebut telah menerapkan prinsip syariah dengan cukup baik. Terbukti mulai dari awal berdirinya usah perhotelan Jamrud Syariah ini belum ada tamu yang berbuat asusila di lingkungan hotel, kemudahan dalam beribadah juga tercipta dengan adanya perlengkapan sholat dan Al-Quran di setiap kamar tamu hotel serta adanya ruang ibadah dilantai satu, serta makanan dan minuman yang halal.

\subsection{Pengelolaan Perhotelan Syariah pada Hotel Jamrud Syariah Pangkalan Bun Ditinjau dari Dewan Syariah Nasional - Majelis Ulama Indonesia Mengenai Peraturan Menteri Pariwisata dan Ekonomi Kreatif Nomor 2 Tahun 2014}

Berdasarkan hasil wawancara pada Hotel Jamrud Syariah pangkalan Bun dalam hal produk berdasarkan Dewan Syariah Nasional-Majelis Ulama Indonesia sebagai berikut, pertama, manajemen usaha Hotel Jamrud Syariah Pangkalan Bun 
telah memiliki Sistem Jaminan Halal. Hal ini dapat dilihat dari makanan dan minuman yang tersaji, kemudian tata tertib yang berlaku di hotel Jamrud Syariah Pangkalan Bun. Kedua, sumber daya manusia, seluruh karyawan memakai seragam yang sopan dan karyawati mengenakan jilbab. Jilbab yang dikenakan karyawati pun harus sopan dan menutup dada. Ketiga, Organisasi Hotel Jamrud Syariah Pangkalan Bun masih memiliki beberapa kekurangan. Organisasi yang dimiliki hotel masih sangat sederhana dan masih dikelola oleh keluarga. Selain itu, Hotel Jamrud Syariah belum memiliki Standart Operating Produce Hotel Jamrud Syariah Pangkalan Bun. Hal ini berakibat sulitnya Hotel Jamrud Syariah untuk meningkatkan dan mengukur standar kompetensi para karyawan dan manajemen yang ada pada Hotel Jamrud Syariah Pangkalan Bun.

\section{KESIMPULAN}

Berdasarkan hasil penelitian dan analisis penelitian yang telah peneliti uraikan tersebut, maka peneliti menarik beberapa kesimpulan yang pertama, pengelolaan Hotel Jamrud Syariah Pangkalan Bun sudah mengalami perkembangan dari tahun ke tahunnya. Hal ini dapat terlihat dari perencanaan, pengorganisasian, pengendalian dan pengawasan yang sudah terorganisir dan terstruktur. Kedua, dalam pengelolaan bisnis perhotelan syariah pada Hotel Jamrud Syariah Pangkalan Bun cukup terlaksana dengan baik, yang mana Hotel Jamrud Syariah Pangkalan Bun sudah memperhatikan prinsip-prinsip syariah pada produk yang ditujukan kepada tamu hotel maupun karyawan, Hotel Jamrud Syariah Pangkalan Bun cukup baik dalam memberikan pelayanan kepada tamu hotel, pengelolaan bisnis hotel Jamrud Syariah Pangkalan Bun telah menerapkan prinsip-prinsip syariah khususnya dalam hal busana karyawan akan tetapi hotel Jamrud Syariah Pangkalan Bun belum memiliki Standar Operasional Perusahaan (SOP) untuk menjaga standar kompetensi yang harus dimiliki oleh setiap karyawan hotel.

\section{DAFTAR PUSTAKA}

\section{Daftar Buku :}

Alma, Buchari, dkk. 2009. Manajemen Bisnis Syariah, Bandung: Alfabeta.

Arikunto, Suharsimi. 2003. Manajemen Penelitian, Jakarta: Rineka Cipta.

Blocker, J Edward. 2007. Manejemen Biaya Penekanan Strategis, Jakarta, Salemba Empat.

Bungin, Burhan. 2011. Metodologi Penelitian Sosial: Format-Format kuantitatif dan Kualitatif, Surabaya: Airlangga University Press. 
Effendi, Usman. 2014. Asas Manajemen, Jakarta: Rajawali Press.

Hardjanto, Amirullah Imam. 2005. Pengantar Bisnis, Yogyakarta: Graha Ilmu.

Ibrahim. 2015. Metodologi Penelitian Kualitatif Panduan Penelitian beserta Contoh Proposal Kualitatif, Bandung: Alfabeta.

Kotler, Philip. 2009. Manajemen Pemasaran, Jakarta: Gelora Aksara Pratama.

Moleong, Lexy J. 2002. Metodologi Penelitian Kualitatif, Bandung: PT RosdaKarya.

Mariyana, Rita dan Ali Nugraha. 2013. Pengelolaan Lingkungan Belajar, Jakarta, Kencana Prenada Media Group.

Perwani, Sri. 200o. Teori dan Petunjuk House Kepping untuk Akademik Perhotelan Make Up Room, Jakarta: Gramedia Pustaka Utama.

Riani, Wahyu. 2009. Manajemen Operasi Jasa, Yogyakarta, Graha Ilmu.

Sambodo, Agus dan Bagyono. 2006. Dasar-dasar Kantor Depan Hotel, Yogyakarta, CV Andi Offset.

Sofyan, Riyanto. 2012. Prospek Bisnis Pariwisata Syariah, Jakarta: Republika.

Sofyan, Riyanto. 2011. Bisnis Syariah, Mengapa Tidak? Jakarta, PT Gramedia Pustaka Utama.

Umar, Husein. 2000. Riset pemasaran dan Perilaku Konsumen, Jakarta, Pt Gramedia Pustaka Utama.

Utami, I Gusti Bagus Ray dan Ni Made Eka Mahadewi. 2002. Metodologi Penelitian Pariwisata dan Perhotelan, Yogyakarta, Andi Offset.

Wahjono, Sentot Imam. 2008. Manajemen Tata kelola Organisasi Bisnis, Jakarta: PT Indeks.

\section{Referensi Lainnya:}

Adimas Fahmi Firmansyah, Praktek Etika Bisnis Islam (Studi Kasus Pada Toko Santri Syariah Surakarta), Yogyakarta, Universitas Islam Negeri Sunan Kalijaga, 2013.

Fitri Kartini, Analisis Faktor-Faktor yang Mempengaruhi Keputusan Tamu Hotel dalam Layanan Namira Hotel Syariah, Yogyakarta: UIN Sunan Kalijaga, 2014. 
Tia Puspita Sari, Pengaruh Produk Hotel Syariah Terhadap Keputusan Tamu Menginap di Hotel Betawi DKI Jakarta, Jakarta: Universitas Pendidikan Indonesia, 2014. 